\title{
Frequency of alleles associated with celiac disease in patients with autoimmune thyroid disease
}

\section{Frequência dos alelos associados com a doença celíaca em portadores de doenças autoimunes da tireoide}

\author{
Clédia Silveira Flores da SILVA 1 (ID) 0000-0002-9289-304X \\ Natalia Rodrigues CARDOZO ${ }^{1}$ (ID) 0000-0001-5679-3861 \\ Raíssa ZANATTA2 ID 0000-0002-7747-3274 \\ Augusto SCHNEIDER ${ }^{1}$ ID) 0000-0002-3410-2860 \\ Carlos Castilho de BARROS ${ }^{1}$ ID 0000-0002-6926-734X \\ Fabiana Torma BOTELHO ${ }^{1}$ ID 0000-0003-3811-6212
}

A B S T R A C T

\section{Objective}

To determine the frequency of Human leukocyte antigen alleles and to verify the association of the presence of these alleles with symptoms and other diseases related to celiac disease in patients with autoimmune thyroid diseases.

\section{Methods}

A questionnaire on the symptoms and diseases associated with celiac disease was applied. Genomic deoxyribonucleic acid was extracted by collecting cells from the oral mucosa. The alleles (DQA1*0501; DQB1*0201; DRB1*04) were identified by means of the polymerase chain reaction.

\footnotetext{
1 Universidade Federal de Pelotas, Programa de Pós-Graduação em Nutrição e Alimentos, Laboratório de Nutrigenômica. R. Gomes Carneiro, n. 1, Campus Porto, 96010-900, Pelotas, RS, Brasil. Correspondence to: FT Botelho. E-mail: <fabibotelho@hotmail.com>.

2 Universidade Federal de Pelotas, Faculdade de Nutrição, Departamento de Nutrição. Pelotas, RS, Brasil.

How to cite this article

Silva CSF, Cardozo NR, Zanatta R, Schneider A, Barros CC, Botelho FT. Frequency of alleles associated with celiac disease in patients with autoimmune thyroid disease. Rev Nutr. 2021;34e200034. https://doi.org/10.1590/1678-9865202134e200034
} 


\section{Results}

A total of 110 patients with autoimmune thyroid diseases participated in this study. It was observed that $66.4 \%$ of the individuals carried at least one of the alleles assessed and that $58.2 \%$ of the individuals were positive for at least one of the DQ2 alleles (DQA1*0501; DQB1*0201) and out of these 18.2\% were positive for both DQ2 alleles (DQA1*0501; $\mathrm{DQB} 1 * 0201)$. With regard to DQ8 (DRB1*04), $21.8 \%$ of the studied population was positive for this allele and $3.6 \%$ was positive for both DQ2 (DQA1*0501; DQB1*0201) and DQ8 (DRB1*04). A significant association was found between the presence of the DRB $1 * 04$ allele and gastrointestinal symptoms $(p=0.02)$. A significant association of the DRB 1 *04 allele with type 1 diabetes mellitus ( $p=0.02)$ was observed.

\section{Conclusion}

The genetic profiles most commonly associated with celiac disease, such as DQ2 (DQA1*0501; DQB1*0201) and DQ8 (DRB1*04) were around $20.0 \%$ prevalent in the studied population. These are risk haplotypes for celiac disease especially when symptoms and diseases related to celiac disease are present. Therefore, it is important to screen patients to investigate a potential diagnosis for celiac disease.

Keywords: Autoimmune thyroiditis. Celiac disease. HLA antigens.

\section{RE S U M O}

\section{Objetivo}

Determinar a frequência dos alelos do Human leukocyte antigen e verificar a associação da presença desses alelos com sintomas e outras doenças relacionados à doença celíaca em portadores de doenças autoimunes da tireoide.

\section{Métodos}

Aplicou-se um questionário relacionado aos sintomas e doenças associados à doença celíaca. O ácido desoxirribonucleico genômico foi extraído por meio da coleta das células da mucosa bucal. Os alelos (DQA1*0501; DQB1*0201; DRB1*04) foram identificados por meio da reação em cadeia da polimerase.

\section{Resultados}

Participaram deste estudo 110 portadores de doenças autoimunes da tireoide. Observou-se que 66,4\% dos indivíduos carregavam pelo menos um dos alelos estudados e que 58,2\% dos indivíduos eram positivos para pelo menos um dos alelos DQ2 (DQA1*0501; DQB1*0201) e destes 18,2\% foram positivos para ambos alelos do DQ2(DQA1*0501; $D Q B 1$ *0201). Com relação ao DQ8 (DRB1*04), 21,8\% da população estudada eram positivos para esse alelo e 3,6\% eram positivos tanto para o DQ2 (DQA1*0501; DQB1*0201) quanto para o DQ8 (DRB1*04). Foi encontrada associação significativa da presença do alelo DRB1*04 com os sintomas gastrointestinais $(p=0,02)$. Houve associação significativa do alelo DRB1*04 com diabetes mellitus tipo $1(p=0,02)$.

\section{Conclusão}

O perfil genético mais fortemente associado à doença celíaca, tais como DQ2 (DQA1*0501; DQB1*0201) e DQ8 $(D R B 1 * 04)$ estavam presentes em torno de 20,0\% da população estudada, estes são haplótipos de risco para doença celíaca e principalmente na presença de sintomas e doenças relacionadas à doença celíaca. Sendo assim, é importante realizar o rastreamento para investigar um possível diagnóstico para doença celíaca.

Palavras-chave: Tireoidite autoimune. Doença celíaca. Antígenos HLA.

\section{NTRODUCTION}

Celiac Disease (CD) is characterized by an autoimmune enteropathy triggered by the ingestion of gluten in genetically predisposed individuals with Human Leukocyte Antigen (HLA) haplotypes, mainly HLA-DQ2 or HLA-DQ8 [1]. Celiac disease has become ever more frequent in the population in general; it is present in about $1 \%$ of the global population, and its prevalence in European populations varies from $1 \%$ to $2 \%$. In Brazil it is estimated that about 300 thousand individuals have been diagnosed with the disease, with a higher incidence in the Southeastern region. The pathology is also predominantly observed in women, at a ratio of $2: 1$ in the population [2]. 
Gluten is present in cereals such as wheat, rye, barley and its derivatives; its ingestion by CD individuals can cause lesions in the small intestine mucosa, decreasing the intestinal absorption surface area and interfering with the absorption of micronutrients such as fat-soluble vitamins, iron, vitamin B12 and folic acid [3]. Individuals with CD can present with gastrointestinal symptoms such as weight loss, growth retardation, osteoporosis, anemia, malabsorption of nutrients, chronic constipation and abdominal pain [4]. In addition to gastrointestinal symptoms, CD can also cause extraintestinal symptoms such as arthralgia/ arthritis, alopecia, fatigue, headache, mouth sores, muscle pain, depression, skin rashes, neuropathy, short stature, late puberty and infertility [5].

Therefore, Celiac disease diagnosis is considered difficult, as the disease can be mistaken with other enteropathies also due to the multiplicity of gastrointestinal and extraintestinal symptoms, which may delay the diagnosis [6]. The gold standard for diagnosing CD is intestinal endoscopic biopsy. Through this histological evaluation we can verify the different signs such as: the presence of villous atrophy, crypt hyperplasia, decreased height of enterocytes and the presence of inflammatory infiltrates in the small intestine mucosa [7].

The etiology of CD is composed of environmental and genetic factors. Regarding the genetic factors, HLA conveys $40 \%$ of the genetic variance [8]. Most patients (90\%) carry DQ2 heterodimers encoded by DQA $1 * 05 / D Q B 1 * 02$ alleles and a minority (5\%) carry DQ8 encoded by DQA $1 * 03 / D Q B 1 * 0302$ and (5\%) at least one of the two alleles DQ2 (usually the DQB1*0201) [9]. In view of the negative predictive value, HLA typing has been used as a screening tool for high-risk populations [10].

Investigating the presence of these $C D$ genetic risk alleles can help patients with type 1 diabetes mellitus (DM1), Down syndrome, Turner syndrome and Autoimmune Thyroid Diseases (AITD) to potentially diagnose $C D$ and, consequently, after treatment with a gluten-free diet, improve quality of life and reduce the medication dosage $[10,11]$. In addition, failure to treat CD can cause harm such as small intestine adenocarcinoma, esophageal cancer, B cell lymphomas and intestinal T cell lymphomas [12].

The incidence of CD in patients with AITD can be up to ten-fold the general population [13]. It is believed that these autoimmune disorders populations are at an increased risk for disease development due to shared HLA typing [14].

Therefore, the present study aims to determine the frequency of HLA-DQ2 (DQA1*0501 and DQB1*0201) and HLA-DQ8 (DRB1*04) and also to assess the association of these alleles with symptoms and other diseases related to $C D$ in patients with autoimmune thyroid diseases.

\section{METHODS}

This is a cross-sectional analytical study, which was carried out at the Nutrition Clinic and the Endocrinology Clinic at the Universidade Federal de Pelotas (UFPel, Federal University of Pelotas). Participants were selected on a non-random basis for convenience. The sample was calculated with a 95\% confidence level using the $\mathrm{G}$ *Power statistical program, obtaining a convenience sample of 110 individuals. In order to be included in the study, individuals had to be patients at the Nutrition Clinic or at the UFPel Endocrinology Clinic, be of any age and have any AITD with medical diagnosis and/or use of drugs for the treatment of AITD described in the outpatient medical record.

The investigation project was submitted to the Research Ethics Committee (REC), according to the rules established by Resolution n. 466, dated December 12, 2012 and aiming to comply with the Code of 
Ethics for Nutritionists, being approved by the Brazil platform under number CAAE 02227718300005316. The research and data collection were performed after approval of the project by the REC and signing of the Free and Informed Consent Form (FICF) by AITD patients.

Data were retrieved from the medical records of those individuals who attended the selected outpatient clinics for the study and, over a period of three months, patients were asked to participate in the study and, thus, 110 patients were included. Subsequently, oral mucosa cells were collected from all individuals who agreed to participate in the study and signed the informed consent form. This procedure required the individual to rinse his/her mouth with drinking water and rub the swab several times against the cheek mucosa. Then, the swab was placed back in its sterile packaging and duly identified with the individual's number, and was stored directly on ice, kept in a thermal box for transport to the laboratory, where it was transferred to a freezer until the time for analysis. The oral mucosa cell collection procedure was performed in duplicate so that, if necessary, the analyses could be repeated. After the extraction of the genetic material, a questionnaire adapted from the questionnaire by Cassol et al. [15] was used. It comprises study participants' sociodemographic gastrointestinal, extraintestinal symptoms and CD-related diseases questions.

The genomic Deoxyribonucleic Acid (DNA) extraction method, adapted from the method described by Miller et al. [16], was used. The amplified alleles in this study were DQA 1*0501/DQB1*0201 (HLA-DQ2) and DRB $1 * 04$ (HLA-DQ8). The DNA amplification method used was based on the method described by Cambien et al. [17]. The primers used are described in Table 1.

Table 1 - Characteristics of primers used for PCR.

\begin{tabular}{llc}
\hline Primer & Sequence & Size of PCR products \\
\hline DQA 1*0501 & 5'-AGCAGTTCTACGTGGACCTGGGG-3' & $144 \mathrm{bp}$ \\
DQB1*0201 & 5'-GGTAGAGTTGGAGCGTTTAATCAGA-3' & $110 \mathrm{bp}$ \\
& 5'-CGCGTGCGTCTTGTGAGCAGAAG-3' & \\
DRB1*04 & 5'-GGCGGCAGGCAGCCCCAGCA-3' & $217 \mathrm{bp}$ \\
ECAf & 5'-GGTTAAACATGAGTGTCATTTCTTAAAC3' & $190 \mathrm{bp}$ \\
ECAr & 5'-GTTGTGTCTGCAGTAGGTGTC-3' & $490 \mathrm{bp}$ \\
\hline
\end{tabular}

Note: BP: Base Pairs; DQA1*0501 and DQB1*0201 for HLA-DQ2; DRB1*04 for HLA-DQ8; hECAf and hECAr: Amplification Controls; PCR: Polymerase Chain Reaction.

Source: Adapted from Yoshida et al. [34].

To confirm the size of the amplified fragment, 10 $\mu$ l of the Polymerase Chain Reaction (PCR) product was applied on a 3\% agarose gel and were submitted to horizontal electrophoresis in Tris/Borate/ Ethylenediamine tetraacetic acid (TBE) running buffer. As a molecular weight marker, 100 bp DNA Ladder ${ }^{\circledR}$ (Biolabs) base pairs were used.

The genomic Deoxyribonucleic Acid (DNA) visualization was performed with Sybr Safe (Invitrogen ${ }^{\circledR}$ ) in a UV light transilluminator. For the first reaction (DQA $1{ }^{*} 0501$ and $\mathrm{DQB} 1{ }^{*} 0201$ ), two products were expected, 144 and $110 \mathrm{bp}$; in the second reaction (DRB1*04), it was expected that a single 217 bp product would be observed.

The frequencies of responses in the questionnaires and of the alleles found were entered in a Microsoft Office Exce ${ }^{\circledR} 2010$ and the statistical analysis was performed using the STATA 14.0 software, using 
the Chi-Square test with Fisher's Exact test to analyze the allele prevalence (DQA1*0501; DQB1*0201 and $\left.\mathrm{DRB} 1{ }^{*} 04\right)$ in connection with symptoms and diseases. To compare patients who experienced gastrointestinal symptoms with the presence or absence of alleles encoding HLA-DQ2 and HLA-DQ8, the Chi-square test was used in the Graph Pad 6.0 program. All results of the analyses were considered significant when $p$ was $<0.05$.

\section{RE S U L T S}

A total of 110 patients, with a mean age of $46 \pm 22.30$ years, the majority between 41 and 65 years (42.7\%) participated in this study. There was a predominance of females (75.4\%), Caucasian ethnicity (84.6\%) and hypothyroidism (95.4\%). Regarding education, incomplete elementary school had the highest incidence $(47.3 \%$ of the study population).

The most prevalent gastrointestinal symptoms related to CD in these AITD individuals were: abdominal distension (40.0\%), abdominal pain (15.5\%) and diarrhea (9.1\%). As for extraintestinal symptoms, the most reported ones were skin lesions (9.1\%), weight loss (8.2\%) and anemia (7.3\%) (Table 2). As for other disorders related to CD, the frequency described was osteoporosis (7.3\%), DM1 (6.4\%), lactose intolerance (3.6\%) and rheumatoid arthritis (3.6\%) (Table 2).

Table 2 - Clinical characteristics of patients with autoimmune thyroid disease treated at the Endocrinology and Nutrition Outpatient Clinics of Universidade Federal de Pelotas. Pelotas (RS), 2019.

\begin{tabular}{|c|c|c|}
\hline Variables & $\mathrm{n}$ & $\%$ \\
\hline \multicolumn{3}{|l|}{ Symptoms } \\
\hline Abdominal distension (bloating) & 44 & 40 \\
\hline Abdominal pain & 17 & 15.5 \\
\hline Diarrhea & 10 & 9.1 \\
\hline Skin lesions & 10 & 9.1 \\
\hline Slimming & 9 & 8.2 \\
\hline Anemia & 8 & 7.3 \\
\hline \multicolumn{3}{|l|}{ Autoimmune thyroid diseases } \\
\hline Hypothyroidism & 105 & 95.4 \\
\hline Hyperthyroidism & 5 & 4.6 \\
\hline \multicolumn{3}{|l|}{ Disorders related to celiac disease } \\
\hline Osteoporosis & 8 & 7.3 \\
\hline Diabetes mellitus 1 & 7 & 6.4 \\
\hline Lactose intolerance & 4 & 3.6 \\
\hline Rheumatoid arthritis & 4 & 3.6 \\
\hline Down's syndrome & 2 & 1.8 \\
\hline Turner syndrome & 1 & 0.9 \\
\hline
\end{tabular}

Note: $n=110$.

Regarding the distribution of the three studied risk alleles related to HLA, it was observed that $66.4 \%$ of the individuals in the sample carried at least one of these alleles. Regarding HLA-DQ2, it was found that $58.2 \%$ of the individuals were positive for at least one of the HLA-DQ2 alleles (DQA $1 * 0501$ or DQB1*0201). Out of these, 25.5\% were positive only for HLA-DQ2 (DQA1*0501), 18.2\% were positive for both HLA-DQ2 alleles (DQA1*0501 and DQB1*0201) and 14.5\% were positive for HLA- DQ2 only (DQB1*0201) (Table 3). 
In relation to HLA-DQ8 (DRB1*04), $21.8 \%$ of the studied population was positive for this allele (Table 3). As for the genotypic distribution, 3.6\% was positive for both HLA-DQ2 alleles (DQA1 *0501 and DQB1*0201) as well as for HLA-DQ8 (DRB1*04) (Table 3).

When a relationship was made between the HLA-DQ8 (DRB1*04) presence and gastrointestinal symptoms (abdominal distension, abdominal pain and diarrhea), a significant association was observed $(p=0.02)$, showing that patients who had this allele had at least one or more of the gastrointestinal symptoms reported above. When analyzing each symptom individually with the presence or not of the DRB1*04 allele, there was a significant association of the $\mathrm{DRB} 1{ }^{*} 04$ allele presence with abdominal distension $(p<0.01)$, showing that individuals who had this allele rather than other alleles studied, presented more frequently with the abdominal distention symptom (Table 4). There was also a significant association between the presence of DRB 1*04 with DM1 ( $p=0.02)$, indicating an association of this allele with another autoimmune disease (Table 5). No significant association was found between the alleles studied and patients with AITD, and there were no significant associations between HLA-DQ2 and gastrointestinal symptoms and other CD-related diseases (Table 5).

When specifically assessing gastrointestinal symptoms positive patients with or without the presence of alleles encoding HLA-DQ2 and DQ8, it was observed that patients who experienced gastrointestinal symptoms (abdominal distension, abdominal pain and diarrhea) had a significant association $(p=0.04)$ with the concomitant presence of the DQA1*0501 (HLA-DQ2) and DRB1*04 (HLA-DQ8) alleles ( $p=0.04)$.

Table 3 - Genetic profile of patients with autoimmune thyroid disorders observed at the Endocrinology and Nutrition Outpatient Clinics of Universidade Federal de Pelotas. Pelotas (RS), 2019.

\begin{tabular}{lcc}
\hline Variables & $\mathrm{n}$ & $\%$ \\
\hline DQ2(DQA1*0501) positive & 28 & 25.5 \\
DQ2 (DQA1*0501; DQB1*0201) positive & 20 & 18.2 \\
DQ2 (DQB1*0201) positive & 16 & 14.5 \\
DQ2(DQA1*0501; DQB1*0201) negative & 46 & 41.8 \\
DQ8(DRB1*04) positive & 24 & 21.8 \\
DQ8 (DRB1*04) negative & 86 & 78.2 \\
DQ2(DQA1*0501;DQB1*0201)+DQ8 (DRB1*04) positive & 4 & 3.6 \\
\hline
\end{tabular}

Note: $n=110$

Table 4 - Relationship of the genetic profile with the presence of symptoms associated with celiac disease, in patients with autoimmune thyroid diseases.

\begin{tabular}{|c|c|c|c|c|c|c|c|c|c|c|}
\hline \multirow{3}{*}{ Variables } & \multicolumn{10}{|c|}{ Genetic profile } \\
\hline & \multicolumn{2}{|c|}{ DQ2+ } & \multicolumn{2}{|c|}{ DQ2- } & \multirow{2}{*}{$p$-value } & \multicolumn{2}{|c|}{ DQ8+ } & \multicolumn{2}{|c|}{ DQ8- } & \multirow{2}{*}{$p$-value } \\
\hline & $\mathrm{n}$ & $\%$ & $n$ & $\%$ & & $\mathrm{n}$ & $\%$ & $\mathrm{n}$ & $\%$ & \\
\hline Gastrointestinal symptoms & 31 & 28.2 & 20 & 18.2 & 0.60 & 6 & 5.5 & 45 & 40.9 & 0.02 \\
\hline Abdominal distension & 27 & 24.5 & 17 & 15.5 & 0.58 & 4 & 3.6 & 40 & 36.4 & $<0.01$ \\
\hline Abdominal pain & 7 & 6.4 & 10 & 9.1 & 0.12 & 3 & 2.7 & 14 & 12.7 & 0.65 \\
\hline Extraintestinal Symptoms & 16 & 14.5 & 10 & 9.1 & 0.69 & 4 & 3.6 & 22 & 20.0 & 0.36 \\
\hline Skin lesions & 5 & 4.5 & 5 & 4.5 & 0.58 & 1 & 0.9 & 9 & 8.2 & 0.34 \\
\hline Slimming & 6 & 5.5 & 3 & 2.7 & 0.59 & 2 & 1.8 & 7 & 6.4 & 0.97 \\
\hline Anemia & 6 & 5.5 & 2 & 1.8 & 0.31 & 1 & 0.9 & 7 & 6.4 & 0.50 \\
\hline Total frequency & 64 & 58.2 & 46 & 41.8 & - & 24 & 21.8 & 86 & 78.2 & - \\
\hline
\end{tabular}

Note: HLA-DQ2=DQA1*0501 e DQB1*0201; HLA-DQ8=DRB1*04; Chi-Square test with Fisher's Exact test. 
Table $\mathbf{5}$ - Relationship of the genetic profile with the presence of diseases associated with celiac disease, in patients with autoimmune thyroid diseases.

\begin{tabular}{|c|c|c|c|c|c|c|c|c|c|c|}
\hline \multirow{3}{*}{ Variables } & \multicolumn{10}{|c|}{ Genetic profile } \\
\hline & \multicolumn{2}{|c|}{ DQ2+ } & \multicolumn{2}{|c|}{ DQ2- } & \multirow{2}{*}{$p$-value } & \multicolumn{2}{|c|}{ DQ8+ } & \multicolumn{2}{|c|}{ DQ8- } & \multirow{2}{*}{$p$-value } \\
\hline & $n$ & $\%$ & $\mathrm{n}$ & $\%$ & & $\mathrm{n}$ & $\%$ & $n$ & $\%$ & \\
\hline Hypothyroidism & 62 & 56.4 & 43 & 39.1 & 0.39 & 23 & 20.9 & 82 & 74.5 & 0.92 \\
\hline Hyperthyroidism & 2 & 1.8 & 2 & 1.8 & 0.73 & 1 & 0.9 & 3 & 2.7 & 0.87 \\
\hline Autoimmune disorders & 9 & 8.2 & 5 & 4.5 & 0.62 & 4 & 3.6 & 10 & 9.1 & 0.51 \\
\hline Osteoporosis & 4 & 3.6 & 4 & 3.6 & 0.63 & 0 & 0.0 & 8 & 7.3 & 0.12 \\
\hline Type 1 diabetes mellitus & 5 & 4.5 & 2 & 1.8 & 0.46 & 4 & 3.6 & 20 & 18.2 & 0.02 \\
\hline Lactose intolerance & 3 & 2.7 & 1 & 0.9 & 0.49 & 1 & 0.9 & 3 & 2.7 & 0.87 \\
\hline Rheumatoid arthritis & 2 & 1.8 & 2 & 1.8 & 0.74 & 0 & 0.0 & 4 & 3.6 & 0.28 \\
\hline Down's syndrome & 1 & 0.9 & 1 & 0.9 & 0.81 & 0 & 0.0 & 2 & 1.8 & 0.45 \\
\hline Turner's syndrome & 1 & 0.9 & 0 & 0.0 & 0.39 & 0 & 0.0 & 1 & 0.9 & 0.60 \\
\hline Total frequency & 64 & 58.2 & 46 & 41.8 & - & 24 & 21.8 & 86 & 78.2 & - \\
\hline
\end{tabular}

Note: HLA-DQ2= DQA1*0501 e DQB1*0201; HLA-DQ8=DRB1*04; Chi-square test with Fisher's Exact test.

\section{I S C U S S I O N}

Prevalence of HLA-DQ2/HLA-DQ8 in the general population is around $25-35 \%$. Despite the importance of these haplotypes, just their presence is insufficient for the development of CD $[18,19]$. However, approximately 90-95\% of celiac patients are positive for HLA-DQ2, while the rest are positive for HLA-DQ8 [20].

In our investigation, it was observed that $66.4 \%$ of the individuals carried at least one of these alleles; therefore, the frequency of these alleles in patients with AITD is much higher than expected in the general population which is $25-35 \%$ and it gets much closer to these alleles' frequency in the celiac population, which is around $90-95.0 \%$ while $58.2 \%$ of individuals with AITD were positive for at least one of the alleles that make up HLA-DQ2 (DQA1*0501; DQB1*0201) and $21.8 \%$ were positive for HLA-DQ8 (DRB1*04 ). In a study by Spadaccino et al. [21], in which 276 Italian patients with AITD were evaluated, it was found that $2.9 \%$ of the patients were positive for HLA-DQ2 (DQA1*05; DQB1*02) and $0.7 \%$ were positive for HLA-DQ8 (DQA1*03; DQB1*0302), values which are much lower than those found in the present study. In another study by Hadithi et al. [22], which aimed to identify CD in Dutch people with Hashimoto's thyroiditis, it was observed that $50.9 \%$ of the 104 patients with Hashimoto's thyroiditis were HLA-DQ2 (DQA1*05; DQB1*02) and/or HLA-DQ8 (DQA1*03; DQB1*0302) positive; those values are closer to those found in the present study, although even lower.

Although the DQ8 alleles assessed in the aforementioned studies were not the same as in the present study, it is important to understand that susceptibility to CD is associated with the HLA system, especially with the DQA1*05 and DQB1*02 alleles, which encode the DQ2 molecule and the allele DQB1*0302, which encodes the beta chain of the DQ8 molecule. The DQ8 heterodimers are encoded by DQA $1 * 0301$ and $\mathrm{DQB} 1{ }^{*} 0302$ alleles which, due to the binding imbalance, are transmitted together with the DRB 1 *04 allele, forming the haplotype known as DR4-DQ8, an allele analyzed in the present study [9].

In this study, the most cited gastrointestinal symptoms were abdominal distension (40.0\%), abdominal pain (15.5\%) and diarrhea (9.1\%), which are part of the typical symptoms of CD and extraintestinal symptoms such as skin lesions (9.1\%), weight loss (8.2\%) and anemia (7.3\%), which characterize the atypical form of the disease. Cassol et al. [15], in a survey of 145 celiac patients confirmed by biopsy, reported that the main gastrointestinal symptoms were abdominal distension (71.8\%), abdominal pain (71.0\%) and diarrhea 
(65.5\%). As for extraintestinal symptoms, weight loss (51.0\%), anemia (50.3\%) and skin lesions (27.5\%) stood out, in line with the results found in the present study. However, as the population in this study had AITD, with most of the sample individuals having hypothyroidism, the symptoms reported may also be caused by the side effect of the treatment with levothyroxine (T4) which, when used in an overdose, may cause symptoms similar to $C D$, such as weight loss, diarrhea and skin lesions [23]. Nevertheless, the medication guidelines in the dosage section indicate that the medication is very well tolerated by patients and that adverse effect occur only when the doses exceed the amount necessary to control hypothyroidism [24].

Most of the studied population (95.4\%) used this medication in dosages between 05-250 micrograms (from 75 to $112 \mathrm{mcg}$ per day for women and from 125 to $200 \mathrm{mcg}$ per day for men). In addition, it is known that the appropriate treatment for CD can reduce the dosage requirement for this medication possibly due to the improvement of the intestine absorptive function after a gluten-free diet. We also stress the importance of a CD investigation in these patients [25].

As for other disorders related to CD, it was observed that osteoporosis (7.3\%) and lactose intolerance (3.6\%) were reported by the participants with more frequency. Osteoporosis is a common metabolic disorder in CD caused by the decrease in bone mass, due to the malabsorption of calcium and vitamin $D$ in the intestinal system. In children, this can result in rickets, while in adults it can lead to different degrees of osteopenia and osteoporosis [15]. However, there is also a relationship between bone metabolic disorders and genetic factors associated with the HLA class I and II system, such as B7, DR15 and DQ6, which are related to lower bone mineral density in postmenopausal women [26]. Regarding lactose intolerance, it is known that lactase is located on the surface of the intestinal villi, which is commonly injured due to the inflammatory process caused by gluten peptides in celiac patients [27]. This lactose intolerance in celiac patients may occur due to the concomitance of a second disease, such as congenital lactase, hypolactasia or other intestinal diseases [28]. However, we should observe that only $3.6 \%$ of the sample individuals reported lactose intolerance, while gastrointestinal symptoms such as abdominal distension, abdominal pain and diarrhea have been reported by $40.0 \%, 15.5 \%$ and $9.1 \%$ participants, respectively, i.e. values much higher than those reported for lactose intolerance.

With all this diversity of gastrointestinal and extraintestinal symptoms, DC can be mistaken with other enteropathies, which can hinder and extend the diagnosis. Paez et al. [29], demonstrated in their study a delay in the diagnosis of CD of 2 to 3 months for patients with gastrointestinal symptoms and 42 months for the group with non-gastrointestinal manifestations.

In our study, no significant association was found between AITD and the presence of any of the alleles assessed, possibly due to the sample size not being sufficiently large to support this relationship, and also because these alleles are shared between CD and AITD, but are not the only alleles related exclusively to AITD. This relationship between CD and AITD probably reflects the increase in autoimmune diseases in general in $C D$ and can be explained by the presence of shared genetic characteristics. Both HLADQ2 (HLA-DQA1*05; DQB1*02) and HLA-DQ8 (HLA-DQA1*03; DQB1*0302) are common in both thyroid disease and CD [13]. Another explanation would be the presence of non-HLA alleles; genome studies have identified more than 100 non-HLA genes associated with CD [30,31]. However, these non-HLA genes are known to influence autoimmune responses in diseases such as DM1, Graves' disease and hypothyroidism. Therefore, the presence of these genetic risk factors may explain the association between DC and AITD [13].

However, in the literature there are indications of an association between DC and AITD [11, 32]. In investigations to determine the prevalence of CD in patients with AITD, 1.2\% (1:85) of confirmed CD cases involved patients with AITD who were female in their totality and presented with Hashimoto's thyroiditis 
[26]. Ventura et al. [33], evaluated the seroprevalence of CD in individuals with autoimmune thyroiditis and observed $9.3 \%$ CD cases among these patients with AITD.

In this study, AITD patients exhibited a frequency for both HLA-DQ2 alleles (DQA1*0501 and DQB1 *0201) of $18.2 \%$ and 3.6\% and were positive for both HLA-DQ2 alleles (DQA $1 * 0501$ and DQB $1 * 0201$, respectively) and also for the HLA-DQ8 allele (DRB1*04), respectively. Since these are risk haplotypes for $C D$, it is important to screen for possible diagnosis of the disease, especially if these individuals have symptoms and diseases related to $C D$.

Another result of the present study was the significant association of the allele (DRB1*04), marker of the DR4-DQ8 haplotype, with gastrointestinal symptoms (abdominal distension, abdominal pain and diarrhea) (Table 5), showing that people who had this allele experienced at least one of the gastrointestinal symptoms. When each symptom was analyzed separately with the presence or not of the allele, the association of this allele (DRB1*04) with abdominal distension was even greater (Table 5). However, it is known that gastrointestinal symptoms (abdominal distension, abdominal pain and diarrhea) are part of the typical form of CD [9].

There was also a significant association of the DRB1*04 (HLA-DQ8) allele with DM1, showing that the presence of DM1 in patients with AITD was associated with this allele. However, studies with larger populations can assist in providing evidence of this significance, since in the present study, we found $37.2 \%$ $(n=41)$ of these patients with DM1. As for the incidence of CD in patients with DM1, the frequency varies from $5-10 \%$ in the Caucasian population [19]. This relationship is due to the susceptibility genes shared in the HLA region that contribute to the coexistence of DM1 and CD, and the HLA DR3-DQ2 and HLA DR4-DQ8 haplotypes being considered the strongest genetic risk factors for DM1 and CD. The DR4-DQ8 haplotype is found in about $10 \%$ of patients with CD and $70.0 \%$ of patients with DM1. On the other hand, in the present study, $21.8 \%$ of DQ8 alleles were found in patients with AITD.

In view of the results, it is important to increase the number of studies with this and other populations at risk for CD and with a larger number of participants. However, this study observed a predominance of hypothyroidism among AITD, where gastrointestinal and extra-intestinal symptoms were frequently cited, as well as some diseases related to intestinal absorption associated with CD such as osteoporosis and lactose intolerance. Therefore, early diagnosis is important to avoid future complications. In addition, there was an association of all gastrointestinal symptoms together, the isolated abdominal distention symptom and DM1 with the HLA-DQ8 allele, evidencing the importance of conducting a CD investigation mainly in these patients with these alleles.

Furthermore, there is the case of the medication, which, when used in excess, may have side effects similar to the symptoms of CD. When assessing exclusively patients with gastrointestinal symptoms with the presence or not of the alleles association of patients who had symptoms with the presence of one of the HLA-DQ2 alleles and the HLA-DQ8 allele was evidenced, once again highlighting the justification for CD screening in this at-risk population.

A possible diagnosis and correct treatment with the exclusion of gluten in the diet of these patients may reduce the associated gastrointestinal and extraintestinal symptoms, reduce the use of AITD medication, prevent the onset of other autoimmune diseases and intestinal tumors and, consequently, improve their quality of life and prognosis.

\section{CONCLUSION}

Most AITD patients had at least one of the alleles studied, with a higher prevalence of HLA-DQ2 (DQA1*0501 and DQB1*0201), although HLA-DQ8 (DRB1*04) showed a higher level than in other 
populations. In addition, the genetic profile more strongly associated with CD, such as HLA-DQ2 (DQA $1 * 0501$ and DQB1*0201) and HLA-DQ8 (DRB1*04) were present in around $20.0 \%$ of the population studied, although the genetic profile of these associated alleles was 3.6\%. Since, these are risk haplotypes for $C D$ and that the allele (DRB1*04) was significantly associated with gastrointestinal symptoms, which are part of the typical form of CD. Therefore, it is of great importance to screen for a possible diagnosis of celiac disease, since early diagnosis and adequate treatment can help reduce symptoms and the dosage of drugs used in AITD.

\section{CONTRIBUTORS}

CSF SILVA and NR CARDOZO performed the collection of samples, application of questionnaires interpretation of the results, and statistical analysis. R ZANATTA performed the collection of samples, application of questionnaires and interpretation of the results. A SCHNEIDER developed the statistical analysis and review of the article. CSF SILVA, FT BOTELHO, and CC BARROS performed the study design, project design, data interpretation and article writing.

\section{REFERENCES}

1. Freire R, Ingano L, Serena G, Cetinbas M, Anselmo A, Sapone A, et al. Human gut derived-organoids provide model to study gluten response and effects of microbiota derived molecules in celiac disease. Nature. 2019;9(7029):1-15. https://doi.org/10.1038/s41598-019-43426-w

2. Parzanese I, Qehaj D, Patrinicola F, Aralica M, Chirivainternati M, Stifter S, et al. Celiac disease: from pathophysiology to treatment. World J Gastrointest Pathophysiol. 2017;8(2):27-38. https://doi.org/10.4291/wjgp.v8.i2.27

3. Castillo NE, Theethira TG, Leffler. The present and the future in the diagnosis and management of celiac disease. Gastroenterol Rep (Oxf). 2015;3(1):3-11. https://doi.org/ 10.1093/gastro/gou065

4. Mohammdibakhsh R, Sohrabi R, Salemi M, Mirghaed MT, Behzadifar M. Celiac disease in Iran: a systematic review and meta-analysis. Electron Physician. 2017;9(3):3883-95. https://doi.org/10.19082/3883

5. De Re V, Magris R, Cannizzaro R. New insights into the pathogenesis of celiac disease. Front Med (Lausanne). 2017;31(4):137. https://doi.org/10.3389/fmed.2017.00137

6. Husby S, Koletzko S, Korponay-Szabo IR, Kurppa K, Mearin ML, Koninckx CR, et al. European Society for Pediatric Gastroenterology, Hepatology, and Nutrition Guidelines for the Diagnosing Coeliac Disease 2020. J Pediatr Gastroenterol Nutr. 2020;70(1):141-57. https://doi.org/10.1097/MPG.0000000000002497

7. Mills JR, Murray JA. Contemporary celiac disease diagnosis: is a biopsy avoidable? Curr Opin Gastroenterol. 2016;32:80-5. https://doi.org/10.1097/mog.0000000000000245

8. Serena G, Camhi S, Sturgeon C, Yan, S, Fasano A. The role of gluten in celiac disease and type 1 Diabetes. Nutrients. 2015;7(9):7143-62. https://doi.org/10.3390/nu7095329

9. Muniz JG, Sdepanian VL, Neto UF. Prevalence of genetic susceptibility for celiac disease in blood donors in São Paulo, Brazil. Arq Gastroenterol. 2016;53(4):267-72. https://doi.org/10.1590/S0004-28032016000400011

10. Almeida LM, Gandolfi L, Pratesi R, Uenishi RH, Almeida FC, Selleski N, et al. Presence of DQ2.2 associated with DQ2.5 increases the risk for celiac disease. autoimmune diseases. Autoimmune Dis. 2016;5409653. https://doi.org/ $10.1155 / 2016 / 5409653$

11. Sun X, Lu L, Yang R, Li Y, Shan L, Wang Y. Increased incidence of thyroid disease in patients with celiac disease: a systematic review and meta-analysis. Plos One. 2016;11(12):e0168708. https://doi.org/10.1371/journal.pone.0168708

12. Lebwohl B, Sanders DS, Green PHR. Coelic disease. Lancet. 2018;391(10115):70-81. https://doi.org/10.1016/ S0140-6736(17)31796-8

13. Zhao Z, Zou J, Zhao L, Cheng Y, Cai H, Li M, et al. Celiac disease autoimmunity in patients with autoimmune diabetes and thyroid disease among Chinese population. Plos One. 2016;11(7):e0157510. https://doi.org/10.1371/ journal.pone. 0157510

14. Nóbrega YKM. Celiac disease: from the bench to the clinic. In: Nóbrega YKM. Genotype DQ2.5/DQ2.2 ( $\beta 2 / \beta 2)$ and high celiac disease risk development. London: IntechOpen; 2018 [cited 2020 March 13]. Available from: https:// repositorio.unb.br/bitstream/10482/36925/1/CAPITULO_Genotype\%20DQ2.5DQ2.2.pdf 
15. Cassol CA, Pellegrin CP, Wahys MLC, Pires MMS, Nassar SM. Perfil clínico dos membros da associação dos celíacos do Brasil: regional de Santa Catarina (ACELBRA-SC). Arq Gastroenterol. 2007;44(3)257-65. https://doi.org/10.1590/ S0004-28032007000300015

16. Miller SA, Dykes DD, Polesky. A simple salting out procedure for extracting DNA from human nucleated cells. Nucleic Acids Res. 1988;16(3):1215. https://doi.org/10.1093/nar/16.3.1215

17. Cambien F, Poirier O, Lecerf L, Evans A, Cambou JP, Arveiler D, et al. Deletion polymorphism in the gene of angiotensin converting enzyme is a potent risk factor for myocardial infarction. Nature. 1992;359(63696):641-4. https://doi.org/10.1038/359641a0

18. Taylor AK, Lebwohl B, Snyder CL, Green PHR. Gene rewies. In: Taylor AK, Lebwohl B, Snyder CL, Green PHR. Celiac disease. Washignton: University of Washington; 1993-2020 [cited 2020 March 13]. Available from: https://www. ncbi.nlm.nih.gov/books/

19. Caio G, Volta U, Sapone A, Leffler DA, Giorgio R, Catassi C, et al. Celiac disease: a comprehensive current review. BMC Med. 2019;17(142):1-20. https://doi.org/10.1186/s12916-019-1380-z

20. Selleski N, Almeida LM, Almeida FC, Gandolfi L, Pratesi R, Nóbrega YK. Simplifying celiac disease predisposing HLA-DQ alleles determination by the real time PCR method. Arq Gastroenterol. 2015;52(2):143-6. https://doi. org/10.1590/S0004-28032015000200013

21. Spadaccino AC, Basso D, Chiarelli S, Albergoni MP, D'Odorico A, Plebani M, et al. Celiac disease in North Italian patients with autoimmune thyroid diseases. Autoimmunity. 2008;41:116-21. https://doi.org/ 10.1080/08916930701620209

22. Hadithi M, Boer H, Meijer JW, Willekens F, Kerckhaert JA, Heijmans R, et al. Coeliac disease in Dutch patients with Hashimoto's thyroiditis and vice versa. World J Gastroenterol. 2007;13(11):1715-22. https://doi.org/10.3748/wjg.v13.111.1715

23. Martins ACM, Rados DRV, Oliveira EB, Basso J, Brenner JK, Agostinho MR. Telecondutas: hipotireoidismo. Porto Alegre: Telessaúde RS-UFRGS; 2017 [citado 2020 mar 13]. Disponível em: https://www.ufrgs.br/telessauders/documentos/ telecondutas/tc_hipotireoidismo.pdf

24. Merck Group. Levotiroxina sódica. Rio de Janeiro: Merck; 2019 [citado 2019 nov 5]. Disponível em: https://www. merckgroup.com/br-pt/bulario/Levotiroxina\%20s\%C3\%B3dica_Bula_Profissional_01.06.19.pdf

25. Teixeira L, Nisihara R, Utiyama SRR, Bem RS, Marcatto C, Bertolazo M, et al. Screening of celiac disease in patients with autoimmune thyroid disease from Southern Brazil. Arq Bras Endocrinol Metab. 2014;58(6):625-9. https://doi. org/10.1590/0004-2730000003003

26. Li SM, Zhou DX, Liu MY. HLA-A gene polymorphisms contribute to osteoporosis susceptibility in postmenopausal Han Chinese women. Genet Mol Res. 2015;14(3):10322-30. https://doi.org/10.4238/2015.August.28.18

27. Abenavoli L, Delibasic M, Peta V, Turkulov V, De Lorenzo A, Medić-Stojanoska M. Nutritional profile of adult patients whit celiac disease. Eur Rev Med Pharmacol Sci. 2015;19(22):4285-92.

28. Fassio F, Facioni MS, Guagnini F. Lactose Maldigestion, Malabsorption, and Intolerance: a comprehensive review with a focus on current management and future perspectives. Nutrients. 2018;10(11):1-12. https://doi.org/10.3390/ nu10111599

29. Paez MA, Gramelspacher AM, Sinacore J, Winterfield L, Venu M. Delay in diagnosis of celiac disease in patients without gastrointestinal complaints. Am J Med. 2017;130(11):1318-23. https://doi.org/ 10.1016/j.amjmed.2017.05.027

30. Lundin KE, Wijmenga C. Coeliac disease and autoimmune disease-genetic overlap and screening. Nat Rev Gastroenterol Hepatol. 2015;12(9):507-15. https://doi.org/10.1038/nrgastro.2015.136

31. Dieli-Crimi R, Cénit MC, Núñez C. The genetics of celiac disease: a comprehensive review of clinical implications. J Autoimm. 2015;64:26-41. https://doi.org/ 10.1016/j.jaut.2015.07.003

32. Canova C, Pitter G, Ludvigsson JF, Romor P, Zanier L, Zanotti R, et al. Celiac disease and risk of autoimmune disorders: a population-based matched birth cohort study. J Pediatr. 2016;174:146-52. https://doi.org/ 10.1016/j. jpeds.2016.02.058

33. Ventura A, Ronsoni MF, Shiozawa MBC, Dantas-Corrêa EB, Canalli MHBS, Schiavon LL, et al. Prevalence and clinical features of celiac disease in patients with autoimmune thyroiditis: cross-sectional study. São Paulo Med J. 2014;132(6):365-71. https://doi.org/10.1590/1516-3180.2014.1326725

34. Yoshida H, Mitarai T, Kawamura T, Kitajima Y, Miyazaki R, Nagasawa Y, et al. Role of the deletion polymorphism of the angiotensin converting enzyme gene in the progression and therapeutic responsiveness of IgA nephropathy. J Clin Invest. 1995;(96):2162-9. https://doi.org/10.1172/JCI118270 